\title{
Analysis of Old and New Driver's Rear-end Collision Risk
}

\author{
Lian Xiaowei ${ }^{1, a^{*}}$, Liu Fuju ${ }^{2, b}$ and Li Xudong ${ }^{3, c}$ \\ ${ }^{1}$ China Automotive Technology \& Research Center, China \\ ${ }^{2}$ China Automotive Technology \& Research Center, China \\ ${ }^{3}$ China Automotive Technology \& Research Center, China \\ alianxiaowei@catarc.ac.cn, bliufuju@catarc.ac.cn, 'lixudong@catarc.ac.cn
}

\begin{abstract}
Keywords: risk; driving year; rear-end collision; dangerous working condition; analysis
\end{abstract}
\begin{abstract}
Rear-end accident is mainly due to the poor risk of driver's feelings, and cannot be fully aware of the transport of dangerous. In order to study the cause of accidents and the difference between the novice group and experience group in risk perception. This study through the contrast test for inexperienced, moderately experienced and very experienced drivers, studies the driver's risk differences. For each scene, the drivers' level of risk is compared, and the differences between drivers of different driving experience level are analyzed. Whether in dangerous working conditions or accidents, the driver has a different experience difference in quantity of dangerous events. Moreover, this shows that it is necessary to study naturalistic driving in China.
\end{abstract}

\section{Introduction}

The rapidly growing of the quantity of motor vehicle often brings on the rapid increase of traffic demand in cities, which the city road networks always cannot satisfy. Because of road traffic congestion and the irregularity of driver's performance, frequent traffic accidents occur at presents in China. The rear-end accident is one of the most common types.

Autonomous emergency braking (AEB) is an autonomous vehicle active safety system. In a dangerous working condition, emergency brake can be automatically applied to avoid the collision or at least to mitigate its effects [1]. According to a recent study by Insurance Institute for Highway Safety (IIHS), AEB can reduce accidents by up to 27 percent [2]. National governments and most rating agencies pay high attention to AEB. AEB is precisely mainly suitable for the rear-end collision conditions.

In consideration of China complicated traffic situation, we should be made aware of the need for researching on rear-end accidents and corresponding dangerous cases under naturalistic driving conditions in China. The China In-depth Accident Study (CIDAS) database searched from 2011 for 164 car-to-car accidents, where information is sufficient for in-depth analysis. In these accidents there are 77 rear-end accidents and take up 47\%. Besides that, we also collected the cases of vehicle with dangerous working conditions with travelling data recorder in 3 different cities for statistical analysis.

In this paper, the involved dangerous working conditions are extracted from video data through screening and classification. These cases are compared with the accident data, and the risk database involving different driving experience is finally established.

\section{Data collection}

\subsection{Vehicle Instrumentation}

First, Video Vbox Pro is used to collection of real traffic condition in three cities (Beijing, Jinan and Changchun). Video Vbox Pro combines a powerful GPS data logger with a high quality multi-camera video recorder and real-time graphics engine. Four waterproof cameras are mounted (Figure 1). Driving performance data are collected at $100 \mathrm{~Hz}$, for example, speed, lateral acceleration and longitudinal acceleration is recorded at the same time (Figure 2). 


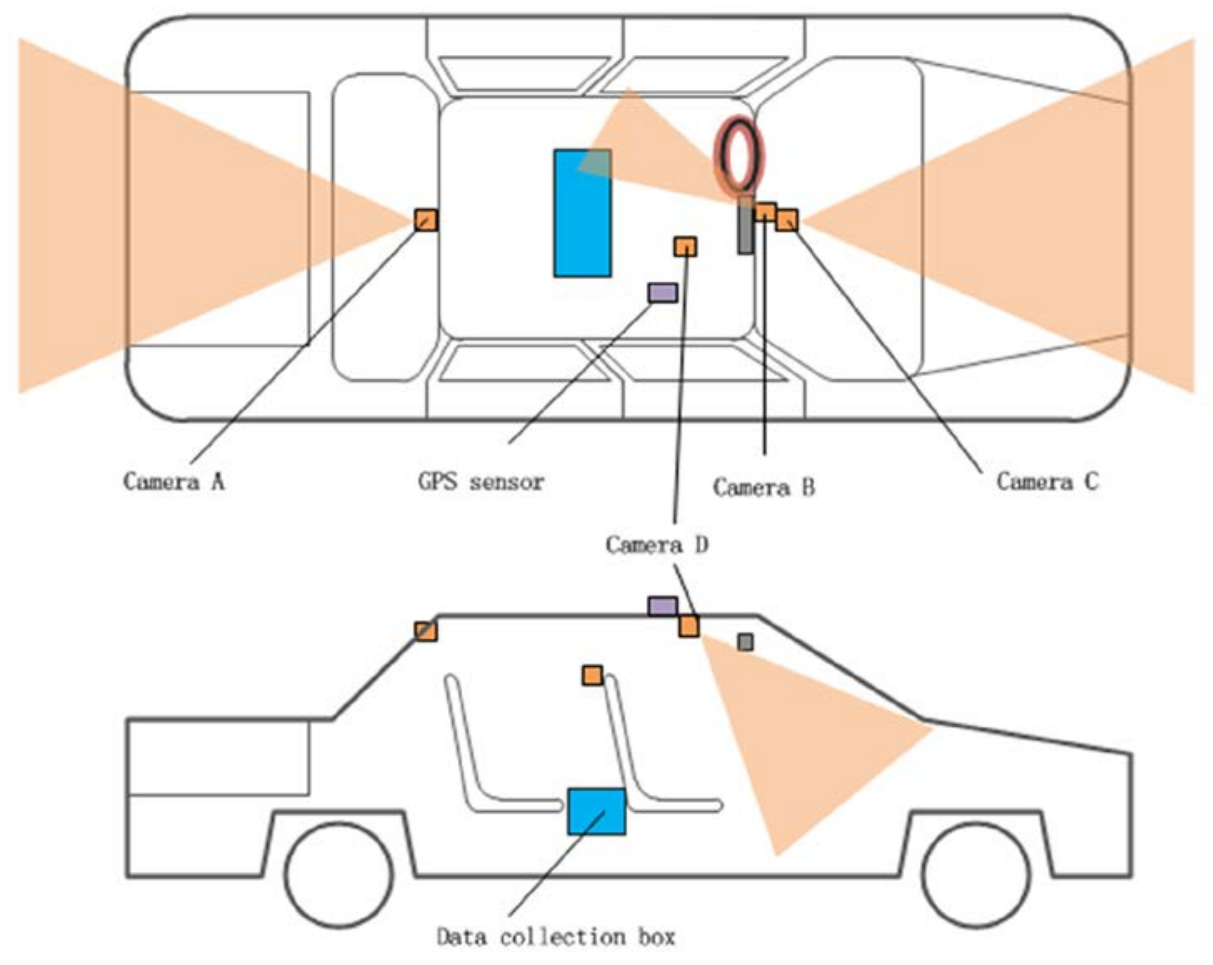

Fig.1. Data collection system

The four camera views are recorded in the instrumented vehicle. A) rear view B) driver's face C) forward view D) over the driver's shoulder view capturing the steering wheel, instrument panel, and the driver's hands and feet.

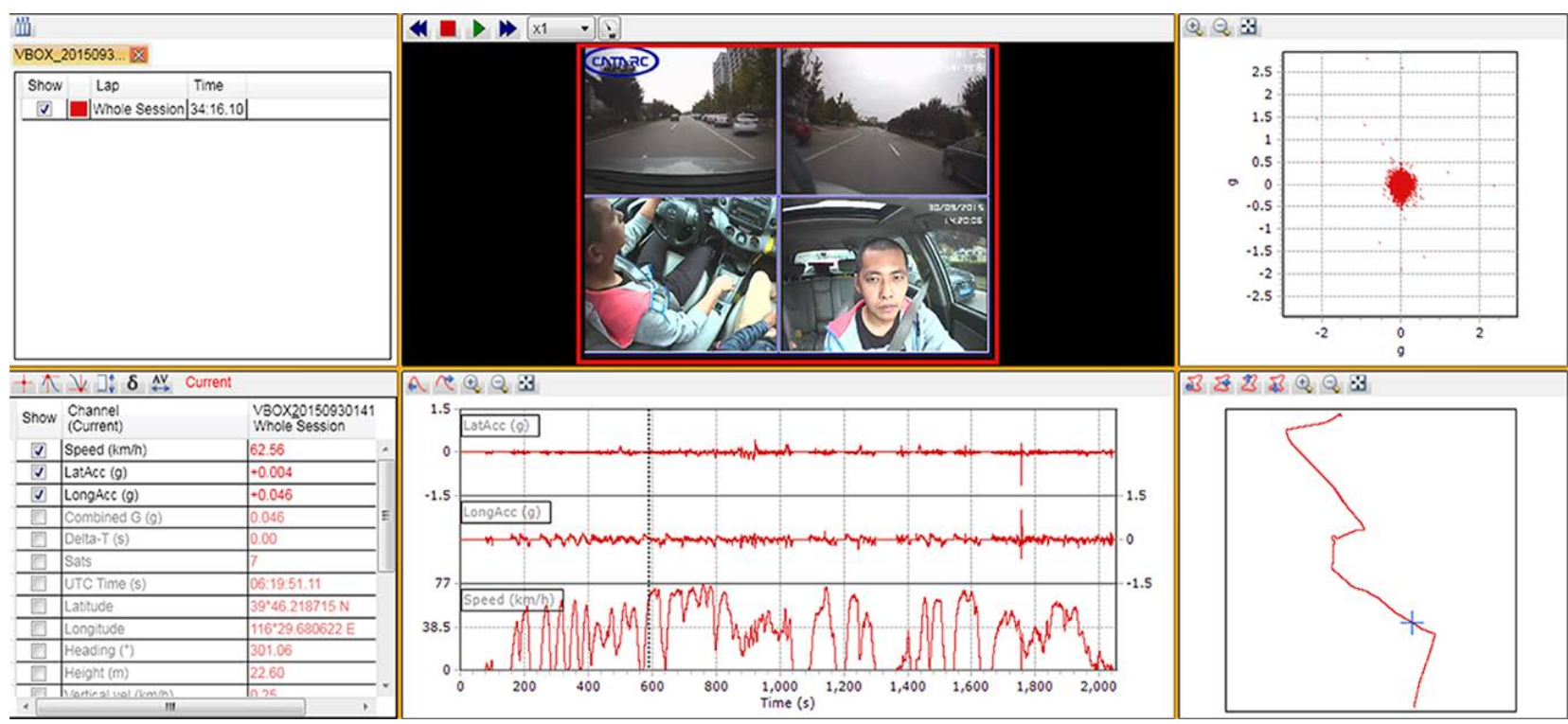

Fig.2. Collection of driving performance data

\subsection{Selection of drivers}

Statistics released by the Ministry of Public Security found that male perpetrators make up $90.61 \%$ in 2014. However, female perpetrators are only one in ten. The percentage of driving years (not more than 3 years) of drivers who involved in accidents is $30.89 \%$. The number from 3 to 10 years is $40.89 \%$ and over 10 years is $28.22 \%$ [3]. According to the distribution functions of the characteristic parameters, we chose 12 drivers from many candidates. The proportion of female drivers is lifted, 
because only one female driver is not convenient to analysis. Ten drivers are numbered 1-10, two female drivers are numbered 11 and 12, and the result is shown below, see Table 1.

Table 1 Selection result of drivers

\begin{tabular}{|c|c|c|c|}
\hline Driving year & Amount & Gender & Serial number \\
\hline$\leq 3$ & 4 & 3 males and 1 female & $1,2,3$ and 11 \\
\hline $3-10$ & 5 & 4 males and 1 female & $4,5,6,7$ and 12 \\
\hline$\geq 10$ & 3 & 3 males & $8,9,10$ \\
\hline
\end{tabular}

\section{Screening and analysis of dangerous cases}

After collecting data, we first selected the working conditions that the longitudinal acceleration or deceleration of magnitude is greater than $0.4 \mathrm{~g}$. Dangerous working conditions are selected by subjective evaluation and classified based on 37 pre-crash scenarios, which NHSTA (National Highway Traffic Safety Administration) released in 2007 [4]. Finally 32 samples of dangerous working conditions are related to rear-end collision danger and chosen for this study.

Table 2 Distribution of dangerous cases

\begin{tabular}{|c|c|c|c|c|c|c|c|c|c|c|c|c|c|}
\hline Serial number & 1 & 2 & 3 & 4 & 5 & 6 & 7 & 8 & 9 & 10 & 11 & 12 & Total \\
\hline $\begin{array}{c}\text { Scenarios } \\
\text { Dead Vehicle }\end{array}$ & 2 & 2 & 1 & 3 & 0 & 2 & 1 & 0 & 2 & 0 & 0 & 0 & 13 \\
\hline $\begin{array}{c}\text { Vehicle(s) } \\
\text { Changing Lanes } \\
\text { - Same Direction }\end{array}$ & 0 & 2 & 1 & 1 & 1 & 1 & 0 & 0 & 0 & 1 & 1 & 1 & 9 \\
\hline $\begin{array}{c}\text { Lead Vehicle } \\
\text { Moving at Lower } \\
\text { Constant Speed }\end{array}$ & 1 & 0 & 0 & 1 & 1 & 1 & 1 & 0 & 0 & 1 & 0 & 0 & 6 \\
\hline $\begin{array}{c}\text { Lead Vehicle } \\
\text { Stopped }\end{array}$ & 0 & 1 & 1 & 1 & 0 & 1 & 0 & 0 & 0 & 0 & 0 & 0 & 4 \\
\hline
\end{tabular}

Table 3 Driver performance measures with different driving experience

\begin{tabular}{|c|c|c|c|c|c|c|c|c|c|}
\hline Performance & \multicolumn{3}{|c|}{ Sample size } & \multicolumn{3}{c|}{$\begin{array}{c}\text { Average braking } \\
\text { duration [sec] }\end{array}$} & \multicolumn{3}{c|}{$\begin{array}{c}\text { Average peak } \\
\text { deceleration [g] }\end{array}$} \\
$\begin{array}{c}\text { Driving } \\
\text { year }\end{array}$ & $\leq 3$ & $3-10$ & $\geq 10$ & $\leq 3$ & $3-10$ & $\geq 10$ & $\leq 3$ & $3-10$ & $\geq 10$ \\
\hline $\begin{array}{c}\text { Scenario } \\
\text { Dead Vehicle }\end{array}$ & 6 & 5 & 2 & 6.86 & 5.32 & 4.8 & 0.43 & 0.48 & 0.48 \\
\hline $\begin{array}{c}\text { Vehicle(s) } \\
\text { Changing Lanes - } \\
\text { Same Direction }\end{array}$ & 5 & 3 & 1 & 6.32 & 4.92 & 4.4 & 0.45 & 0.51 & 0.50 \\
\hline $\begin{array}{c}\text { Lead Vehicle } \\
\text { Moving at Lower } \\
\text { Constant Speed }\end{array}$ & 1 & 4 & 1 & 7.5 & 7 & 4.7 & 0.43 & 0.49 & 0.48 \\
\hline $\begin{array}{c}\text { Lead Vehicle } \\
\text { Stopped }\end{array}$ & 3 & 1 & 0 & 4.2 & 7.1 & & 0.50 & 0.42 & \\
\hline Total & 15 & 13 & 4 & & & & & & \\
\hline
\end{tabular}


In order to distinguish between the severities of events, the concepts of "near-crash" and "incident" are used. A near-crash is referred to a successful crash avoidance event. The danger level of incident is lower than near-crash, but the occurrence frequency is higher [5]. 32 samples include 2 near-crash (Nr. 4 and 9 driver) and 30 incidents. Two near-crash belong to "Lead Vehicle Decelerating”.

\section{Analysis of accident data}

Accident data can provide only pre-crash scenarios and driving years, not braking duration and peak deceleration. 77 rear-end accidents that are searched from the China In-depth Accident Study (CIDAS) database removed five accidents, because they cannot provide complete driver information. These are described in more detail below (Table 4). The ratio of all drivers in CIDAS database group by driving year is about 23:37:40.

Table 4 Distribution of rear-end accidents

\begin{tabular}{|c|c|c|c|c|}
\hline Scenario Driving year & $\leq 3$ & $3-10$ & $\geq 10$ & Total \\
\hline Lead Vehicle Decelerating & 2 & 4 & 2 & 8 \\
\hline $\begin{array}{c}\text { Vehicle(s) Changing Lanes } \\
\text { - Same Direction }\end{array}$ & 2 & 6 & 4 & 12 \\
\hline $\begin{array}{c}\text { Lead Vehicle Moving at } \\
\text { Lower Constant Speed }\end{array}$ & 17 & 6 & 15 & 38 \\
\hline Lead Vehicle Stopped & 5 & 6 & 3 & 14 \\
\hline Total & 26 & 22 & 24 & 72 \\
\hline
\end{tabular}

\section{Result}

Although the number of occurrences decreases not gradually, we also should consider the number of drivers per driving year group. Whether dangerous working conditions or accidents, the average probability of existential risk of new drivers is higher than old drivers.

In dangerous cases, "Lead Vehicle Decelerating” is very easily occurred and the most dangerous scenario. The number of "Vehicle(s) Changing Lanes - Same Direction" is high, because the result of changing lanes is not sure and may be rear-end impact or side impact. The average braking duration of old drivers is considerably shorter, but the average peak deceleration is only slightly higher.

However, the largest number of scenarios is "Lead Vehicle Moving at Lower Constant Speed" and the smallest number is "Lead Vehicle Decelerating". About driver performance measures, we will not discuss this further in this article.

\section{Conclusion}

This fully demonstrates that drivers can be better to control the vehicle and sense the surrounding with the increasing of driving experience. For different scenarios, it leads to two diametrically opposite results. The difference also needs to be researched with more samples. Because accident data have its limitation, naturalistic driving data are more complete. For this reason, it is very necessary to study naturalistic driving in China with more drivers and longer duration.

\section{References}

[1] Wesley Hulshof, Iain Knight, Alix Edwards, Matthew Avery, Colin Grover, Autonomous Emergency Braking Test Results, Thatcham Research, UK, 2013.

[2] Information on http://www.engadget.com 
[3] The Ministry of Pubilc Security of the Pepople's Republic of China, Statistics of Road Traffic Accidents in P.R. of China, 2014.

[4] National Highway Traffic Safety Administration, Pre-Crash Scenario Typology for Crash Avoidance Research, Washington DC, NHTSA, 2007.

[5] National Highway Traffic Safety Administration, The 100 Car Naturalistic Driving Study, Washington DC, NHTSA, 2002. 